\title{
Dinâmica da população de Cardiospermum halicacabum e competição com a cultura da soja
}

\author{
Elemar Voll(1), Alexandre Magno Brighenti ${ }^{(1)}$, Dionísio Luíz Pisa Gazziero ${ }^{(1)}$ e Fernando Storniolo Adegas ${ }^{(2)}$
}

\begin{abstract}
(1)Embrapa Soja, Caixa Postal 231, CEP 86001-970 Londrina, PR. Bolsista do CNPq. E-mail: voll@cnpso.embrapa.br, brighent@cnpso.embrapa.br, gazziero@cnpso.embrapa.br (2)Empresa de Assistência Técnica e Extensão Rural, Rua Bandeira, 570-B, CEP 80035-270 Curitiba, PR. E-mail: adegas@cnpso.embrapa.br
\end{abstract}

\begin{abstract}
Resumo - O balãozinho (Cardiospermum halicacabum), planta daninha introduzida recentemente no Paraná, tem causado perdas econômicas em lavouras de soja no Sul do Brasil. O objetivo deste trabalho foi determinar época e taxa de emergência, competição e sobrevivência de balãozinho na cultura da soja cultivar Embrapa 62, em dois sistemas de manejo. O experimento foi instalado em Londrina, PR, em maio de 1997, e conduzido por três anos consecutivos. Cinco densidades de semeadura de balãozinho (0, 60, 120, 240 e 480 sementes $\left./ \mathrm{m}^{2}\right)$ foram estabelecidas na cultura da soja sob semeadura convencional e direta. O delineamento experimental foi em blocos casualizados, com parcelas subdivididas e quatro repetições. A redução média anual do banco de sementes foi de $61,6 \%$ e 56,4\%, em relação às semeaduras convencional e direta, correspondendo às sobrevivências de seis e sete anos, respectivamente. Taxas anuais de emergência, na ausência de reinfestações, foram maiores em semeadura direta $(42,6 \%, 32,0 \%$ e $5,0 \%)$ do que na convencional $(29,9 \%, 10,9 \%$ e $0,7 \%)$, nos três anos. Perdas de produtividade de soja foram estimadas em $8,1 \%$ com a presença de 10 plantas $/ \mathrm{m}^{2}$ de balãozinho, em $3.549 \mathrm{~kg} / \mathrm{ha}$ de soja. O balãozinho apresenta significativa capacidade de infestação e competição com a soja, tendendo a ser eliminado por condições ambientais que favoreçam o ataque de míldio (Peronospora farinosa).
\end{abstract}

Termos para indexação: banco de sementes, planta daninha, biologia.

\section{Population dynamics of Cardiospermum halicacabum and competition with soybeans}

\begin{abstract}
Balloonvine (Cardiospermum halicacabum) was recently introduced in Paraná State, and it has caused economical damages in soybean crop in the Southern region of Brazil. In order to determine time and emergence rate, the competition and the survival of balloonvine with soybeans cultivar Embrapa 62, grown under two management systems, an experiment was carried out at Londrina, PR, from 1997 to 2000. Five population densities of ballonvine (zero, 60, 120, 240 and $480 \mathrm{seeds} / \mathrm{m}^{2}$ ) were established by sowing seeds in till and no-till managements for soybeans. A split-plot completely randomized block, with four replications, was used. An annual seedbank decrease rate of $61.6 \%$ and $56.4 \%$ was observed for till and no-till, respectively, related to six and seven years survival. Annual rates of emergence, in the absence of reinfestations, were higher in no-till $(42.6 \%, 32.0 \%$ and $5.0 \%)$ than till $(29.9 \%, 10.9 \%$ and $0.7 \%)$, in those three years. Losses of soybeans were estimated at an average of $8,1 \%$ in the presence of 10 plants $/ \mathrm{m}^{2}$ of balloonvine over $3,549 \mathrm{~kg} / \mathrm{ha}$ of soybeans. Balloonvine presents significant infestation and competition hability in the soybean crop, and it tends to be eliminated by environmental conditions that favor downy mildio (Peronospora farinosa) attach.
\end{abstract}

Index terms: seedbank, weed, biology.

\section{Introdução}

O balãozinho (Cardiospermum halicacabum) é uma planta anual, herbácea, trepadeira, glabra ou esparsamente pubescente, de ramos estriados, medindo de 2 a $4 \mathrm{~m}$ de comprimento, com reprodução por sementes. É uma planta daninha que infesta principalmente lavouras perenes, linhas de cerca, pomares e terrenos baldios (Lorenzi, 2000). Souza \& Ruedell (1993) observaram que as infestações das lavouras de soja da região do Planalto Médio, do Alto Uruguai e das Missões do Rio Grande do Sul têm aumentado em cerca de $30 \%$ a $40 \%$. A falta de controle eficaz, as dificuldades na separação mecânica das sementes em peneiras e o comportamento biológico são alguns dos fatores de propagação da espécie. Souza (1995) também observou eleva- 
do grau de dormência das sementes de balãozinho e a melhor profundidade de germinação foi entre 2 e $5 \mathrm{~cm}$. A perda de rendimento de grãos foi de $26 \%$ pela convivência de 10 plantas $/ \mathrm{m}^{2}$ durante o ciclo da soja, em relação à produtividade de $3.888 \mathrm{~kg} / \mathrm{ha}$ da testemunha. Herbicidas, como o lactofen e o fomesafen, propiciaram controle entre $70 \%$ e $90 \%$.

$\mathrm{O}$ balãozinho tem se tornado um sério problema na cultura da soja no Sul dos Estados Unidos (Johnston et al., 1979). Lavouras infestadas com balãozinho não têm sido elegíveis para produção de semente certificada. Equipamentos eletrônicos de seleção e remoção de sementes de balãozinho têm sido testados (Cabrera \& Diaz, 1991).

Johnston et al. (1979) observaram que o balãozinho foi capaz de germinar entre $15^{\circ} \mathrm{C}$ e $40^{\circ} \mathrm{C}$, com temperatura ótima aos $35^{\circ} \mathrm{C}$. A escarificação das sementes com $\mathrm{H}_{2} \mathrm{SO}_{4}$ concentrado durante uma hora não resultou em germinação, tendo alcançado $55 \%$ com três horas de tratamento. Sob condições de simulação de estresse por umidade, a germinação não ocorreu em potenciais hídricos iguais ou inferiores a -2 bars. Com a eliminação do tegumento, a germinação aproximou-se de $80 \%$, indicando que o mesmo limita o processo de embebição necessário à germinação da semente. A germinação máxima ocorreu na profundidade de $1-3 \mathrm{~cm}$ e foi reduzida após os $6 \mathrm{~cm}$.

O objetivo deste trabalho foi determinar a época e a taxa de emergência, a competição e a sobrevivência de balãozinho, na cultura da soja cultivar Embrapa 62, nos sistemas de semeadura convencional e direta.

\section{Material e Métodos}

O experimento foi instalado no campo em maio de 1997, em Londrina, PR, em Latossolo Roxo distrófico, com $75 \%$ de argila e $2,7 \%$ de matéria orgânica. As condições químicas iniciais $(0-20 \mathrm{~cm})$ do solo foram: $\mathrm{pH}\left(\mathrm{em} \mathrm{CaCl}_{2}\right), 5,04 ; \mathrm{Al}, 0,0, \mathrm{~K}, 0,55, \mathrm{Ca}, 5,12, \mathrm{Mg}$, $1,85, \mathrm{H}+\mathrm{Al}, 2,46, \mathrm{~S}, 7,52$ e CTC, $9,98 \mathrm{cmol}_{\mathrm{c}} / \mathrm{dm}^{3} ; \mathrm{Al} \%$, 0,$0 ; \mathrm{V} \%, 75,35 ; \mathrm{C}, 13,6 \mathrm{~g} / \mathrm{dm}^{3} ; \mathrm{P}, 20,5 \mathrm{mg} / \mathrm{dm}^{3}$. O clima da região é do tipo Cfa, segundo Köeppen, ou seja, clima mesotérmico (temperatura média do mês mais frio abaixo de $18^{\circ} \mathrm{C}$ ), subtropical úmido sem estação seca, com verão quente (temperatura do mês mais quente acima de $22^{\circ} \mathrm{C}$ ) (Fundação Instituto Agronômico do Paraná, 1978).

Foram usados dois sistemas de manejo do solo, convencional e semeadura direta, e cinco densidades de semeadura de balãozinho, $0,60,120,240$ e 480 sementes $/ \mathrm{m}^{2}$. O delineamento experimental foi o de blocos casualizados, em esquema de parcelas subdivididas, com quatro repetições. Os sistemas foram dispostos nas parcelas principais e as densidades nas subparcelas. As dimensões das subparcelas foram de 5,0x6,0 m e as parcelas 5,0x30,0 m.

Após a colheita da soja, foi feita a distribuição de calcário dolomítico na dose de 3,0 t/ha (para $\mathrm{V}=70 \%$ ) na superfície do solo, por meio de escarificador e de grade niveladora. Sementes de balãozinho, coletadas em março de 1997, foram semeadas na superfície das subparcelas, conforme casualização das densidades e levemente incorporadas com rastelo, em área sem sementes no solo. No manejo convencional, as sementes foram incorporadas com grade pesada.

O manejo convencional da soja constituiu-se de aração com arado de discos, seguida de grade leve, precedendo a semeadura da soja em até três semanas. $\mathrm{Na}$ semeadura direta, foi feita a dessecação de manejo com paraquat $(1,5 \mathrm{~L} / \mathrm{ha})+$ surfactante (Energic) a $0,05 \%$ v/v. Dois a cinco dias antes da semeadura da soja, foram feitas a segunda gradagem no sistema convencional e outra aplicação de manejo com paraquat $(1,0 \mathrm{~L} / \mathrm{ha})+$ surfactante (Energic) a $0,05 \% \mathrm{v} / \mathrm{v}$, no sistema direto.

A semeadura de soja, cultivar Embrapa 62 (semiprecoce), foi feita em 30/10/1997, 29/10/1998 e 26/10/1999, em linhas distanciadas a $0,5 \mathrm{~m}$, a fim de estabelecer uma densidade entre 15 e 18 plantas $/ \mathrm{m}$. Após a emergência das plantas daninhas, foram aplicados os herbicidas setoxydin + bentazon + óleo mineral (Assist) $(230 \mathrm{~g} / \mathrm{ha}+720 \mathrm{~g} / \mathrm{ha}+1,25 \mathrm{~L} / \mathrm{ha}$, respectivamente), para controle de outras plantas daninhas infestantes, de modo que não afetasse as plantas de balãozinho, não controladas por estes produtos. O controle de lagartas e percevejos da cultura da soja foi feito de acordo com a necessidade. A soja foi colhida na segunda quinzena de março. Anualmente, no mês de maio, foram feitas as semeaduras do trigo cultivar BR-18, na densidade de 100 sementes $/ \mathrm{m}^{2}$, e em meados de setembro, foram feitas as colheitas.

Determinações anuais do banco de sementes de balãozinho foram feitas por amostragem de solo, nos meses de setembro, antes da sua época de germinação, e nos meses de abril, após a colheita da soja, para avaliar reinfestações. A primeira amostragem do solo foi feita em 22/9/1997, após a colheita do trigo, usando 
amostrador tubular de solo com $5 \mathrm{~cm}$ de diâmetro, na profundidade de $0-10 \mathrm{~cm}$. As amostragens posteriores também foram feitas a $0-10 \mathrm{~cm}$ de profundidade, em ambos os sistemas. As amostragens de solo realizadas em setembro permitiram determinar as taxas de emergência do banco de sementes no período anterior e posterior à semeadura da soja e, as amostragens feitas em abril permitiram avaliar as reinfestações.

$\mathrm{O}$ levantamento foi feito apenas na densidade de semeadura máxima de 480 sementes $/ \mathrm{m}^{2}$, coletando-se ao acaso 10 subamostras/parcela para formarem uma amostra composta. As amostras de solo foram identificadas e levadas ao laboratório para os procedimentos de lavagem, flotação e separação das sementes de balãozinho. A lavagem das amostras foi realizada em peneiras de latão, com $20 \mathrm{~cm}$ de diâmetro por $8 \mathrm{~cm}$ de altura e malha de aço inox de $0,5 \mathrm{~mm}$, sob a aspersão de água sob pressão, para eliminar a argila. A parte restante das partículas do solo e material orgânico, incluindo as sementes, foi secada à sombra. A seguir foi feita a flotação da amostra, num becker de $500 \mathrm{~cm}^{3}$, contendo solução saturada de $\mathrm{CaCl}_{2} \cdot 2 \mathrm{H}_{2} \mathrm{O}$ (pureza $75 \%$ ), que elevou as sementes para a porção superior da solução. As sementes foram separadas, enxaguadas, secadas ao ar e contadas, sendo então calculado o número de sementes por $\mathrm{m}^{2}$.

As determinações da emergência de balãozinho, feitas antes e após a semeadura da soja, consistiram de contagens de plantas emergentes feitas antes da aração e, mais próximo à semeadura, antes da gradagem, no sistema convencional. Em semeadura direta, as contagens foram feitas antes das operações de dessecação, uma ou duas, dependendo da reinfestação, e após a semeadura, conforme as condições favoráveis à germinação e emergência de balãozinho. A amostragem foi feita com o auxílio de uma moldura de ferro de $0,5 \times 0,5 \mathrm{~m}$, em número de quatro amostras casualizadas por subparcela. A taxa de emergência das plântulas de balãozinho foi determinada em relação ao número de sementes estimado por metro quadrado.

$\mathrm{Na}$ época da colheita, foram determinados o estande e a altura de plantas de soja, nas linhas centrais $(2,0 \mathrm{~m})$ de cada parcela, bem como o rendimento de grãos (kg/ha), a 13\% de umidade, numa área útil de 3,0x4,0 m.

Os dados foram submetidos à análise de variância e as médias comparadas pelo teste de Tukey a $5 \%$ de probabilidade. Os dados de contagem da emergência de plantas de balãozinho foram transformados em porcen- tagem de emergência e analisados. Foram realizadas análises de regressão não-linear entre densidades de plântulas de balãozinho estabelecidas após a semeadura da soja e rendimentos de grãos de soja, usando a equação hiperbólica segundo Cousens (1985), e a redução anual do banco de sementes, por meio da equação exponencial negativa.

\section{Resultados e Discussão}

O levantamento do banco de sementes de balãozinho indicou que a recuperação das sementes foi de 425 sementes $/ \mathrm{m}^{2}(88,5 \%)$ na semeadura convencional (SC) e 525 sementes $/ \mathrm{m}^{2}(109,4 \%)$ na semeadura direta (SD) do total de 480 sementes $/ \mathrm{m}^{2}$ semeadas inicialmente (Tabela 1). Na SC ocorreu a incorporação parcial das sementes pela aração. Os dados apresentaram uma variabilidade aceitável até o final dos três anos, acusando a redução do banco de sementes, bem como a ausência de reinfestação, que não ocorreu por causa do ataque de míldio (Peronospora farinosa) às folhas do balãozinho, especialmente no primeiro ano. Rao \& Rao (1987), também constataram o ataque deste fungo, que causou a morte de toda a ramada do balãozinho que cobria as plantas de soja e determinando, provavelmente, a redução das reinfestações da espécie. A redução anual do banco de sementes na SC foi de $61,6 \%$ e na SD de 56,4\%; as estimativas do período de sobrevivência, determinadas por equações exponenciais, foram de seis e sete anos, respectivamente, para se atingir $1 \%$ de sementes viáveis no solo (Figura 1). Ao contrário dos resultados deste trabalho, Souza \& Ruedell (1993), no Rio Grande do Sul, constataram que o problema em lavouras tem aumentado anualmente de $30 \%$ a $40 \%$.

Embora os produtores do Norte do Estado do Paraná estejam preocupados com a ocorrência do balãozinho, o problema tende a não se estabelecer, provavelmente, em razão das diferenças de condições ambientais, o que pode indicar ausência de problemas também na Região

Tabela 1. Banco de sementes de balãozinho (número de sementes por $\mathrm{m}^{2}$ ) avaliado por amostragem de solo nas parcelas com 480 sementes $/ \mathrm{m}^{2}$, na profundidade de $0-10 \mathrm{~cm}$, nos manejos de semeadura convencional e direta de soja.

\begin{tabular}{lcccccc}
\hline $\begin{array}{l}\text { Semeadura } \\
\text { da soja }\end{array}$ & \multicolumn{5}{c}{ Datas de amostragem } \\
\cline { 2 - 7 } & $22 / 9 / 1997$ & $22 / 5 / 1998$ & $18 / 9 / 1998$ & $12 / 5 / 1999$ & $20 / 9 / 1999$ & $12 / 5 / 2000$ \\
\hline Convencional & 425 & 112 & 162 & 50 & 62 & 12 \\
Direta & 525 & 300 & 212 & 50 & 100 & 88 \\
\hline
\end{tabular}


Central do Brasil. No entanto, segundo Johnston et al. (1979), merece atenção o fato de que a temperatura ótima de germinação da semente é alta (ótima aos $35^{\circ} \mathrm{C}$ ) em relação a outras espécies e, eliminada a barreira do tegumento no processo de germinação (elevando-se a $80 \%$ ), abundantes chuvas poderiam facilitar a germinação.

Emergências de balãozinho só foram observadas em meados de outubro, antes da época de instalação da cultura da soja e em fins do mês de novembro, com a ocorrência de maior intensidade de chuvas, revelando taxas significativas de emergência em relação ao banco de sementes do ano (Tabela 2). Analisando as taxas anuais de emergência sobre 480 sementes $/ \mathrm{m}^{2}$ inicialmente adicionadas, observa-se que as taxas sempre foram maiores na SD nos três anos $(42,6 \%, 32,0 \%$ e $5,0 \%)$, favorecidas certamente pelas condições de ambiente na superfície do solo, do que na SC $(29,9 \%, 10,9 \%$ e $0,7 \%)$, em que as sementes foram misturadas na camada de 0-20 cm do solo. As condições de germinação de balãozinho, na pré-semeadura da soja, foram mais favoráveis na SD do que na SC, nos anos de 1997/1998 e 1998/1999. Isso ocorreu, provavelmente, em virtude do sistema de manejo e da maior quebra de dormência das sementes. No período de 1999/2000, as taxas de emergência do banco de sementes remanescentes de balãozinho foram menores. Contribuíram para isso a nãoreinfestação do banco de sementes, provavelmente, em virtude do severo ataque de míldio às plantas de balãozinho, o que impediu a formação de novos propágulos, e a maior dormência das sementes rema-

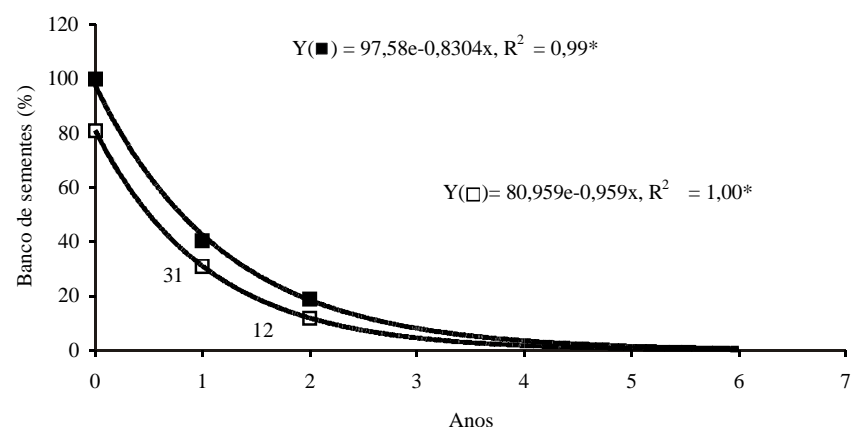

Figura 1. Redução anual do banco de sementes de balãozinho, obtida anualmente no mês de setembro, nos manejos de semeadura convencional ( $\square$ ) e direta ( $\square$ ) da soja, na densidade de 480 sementes $/ \mathrm{m}^{2}$, com projeção de sobrevivência. nescentes. Neste período, ocorreu maior emergência total de balãozinho na SD do que na SC. Comparandose os dois métodos de determinação das taxas de emergência, observa-se maior variabilidade de emergência nas amostras anuais do banco de sementes, do que nas sementes inicialmente adicionadas. Observa-se maiores porcentagens anuais de emergência na $\mathrm{SD}$, em ambos os procedimentos. Souza (1995) observou elevado grau de dormência inicial das sementes, obtendo uma germinação inferior a 10\% e melhor germinação a profundidades de $2-5 \mathrm{~cm}$.

Após a emergência da soja, houve maior emergência de balãozinho na SD, nos três anos de avaliação (Figura 2). As taxas de emergência reduziram-se anualmente de forma linear, apresentando igualmente bom ajuste logarítmico. $\mathrm{O}$ teste $\mathrm{t}_{0,05}$, aplicado aos parâmetros da equação, indicou declínios anuais significativos do número de plantas de 17,8, 9,2 e 3,1 plantas $/ \mathrm{m}^{2}$ na $\mathrm{SD}$, e de $14,1,4,8$ e apenas 0,5 plantas $/ \mathrm{m}^{2}$ na $\mathrm{SC}$, com diferenças significativas entre os manejos, que apresentaram altos índices de ajuste das retas, ou seja, $\mathrm{R}^{2}$ elevados.

Tabela 2. Emergência de balãozinho avaliada antes (porcentagem em relação às 480 sementes adicionadas inicialmente) $\mathrm{e}$ após (porcentagem em relação às sementes determinadas anualmente no banco) a semeadura da soja cultivar Embrapa 62, nos manejos de semeadura convencional (SC) e direta (SD) da $\operatorname{soja}^{(1)}$.

\begin{tabular}{|c|c|c|c|c|}
\hline \multirow[t]{2}{*}{$\begin{array}{l}\text { Época de } \\
\text { avaliação }\end{array}$} & \multicolumn{2}{|c|}{$\begin{array}{c}\text { Antes da } \\
\text { semeadura }\end{array}$} & \multicolumn{2}{|c|}{$\begin{array}{c}\text { Após a } \\
\text { semeadura }\end{array}$} \\
\hline & SC & SD & SC & SD \\
\hline & \multicolumn{4}{|c|}{$1997 / 1998$} \\
\hline 17 DAS & $12,1 \mathrm{aB}$ & $23,5 \mathrm{aA}$ & $13,6 \mathrm{aB}$ & $21,4 \mathrm{aA}$ \\
\hline $2 \mathrm{DAS}$ & $3,7 \mathrm{bA}$ & $1,3 \mathrm{cA}$ & $4,2 \mathrm{bA}$ & $1,2 \mathrm{bA}$ \\
\hline $32 \mathrm{DDS}$ & $14,1 \mathrm{aA}$ & $17,8 \mathrm{bA}$ & $15,9 \mathrm{aA}$ & $16,3 \mathrm{aA}$ \\
\hline \multirow[t]{2}{*}{ Subtotal } & $29,9 \mathrm{aB}$ & $42,6 \mathrm{aA}$ & $33,8 \mathrm{aA}$ & $39,0 \mathrm{bA}$ \\
\hline & \multicolumn{4}{|c|}{$1998 / 1999$} \\
\hline 16 DAS & $6,1 \mathrm{aB}$ & $22,8 \mathrm{aA}$ & $18,1 \mathrm{aB}$ & $51,7 \mathrm{aA}$ \\
\hline $21 \mathrm{DDS}$ & $4,8 \mathrm{aB}$ & $9,2 \mathrm{bA}$ & $14,4 \mathrm{aA}$ & $20,8 \mathrm{bA}$ \\
\hline \multirow[t]{2}{*}{ Subtotal } & $10,9 \mathrm{bB}$ & $32,0 \mathrm{bA}$ & $32,4 \mathrm{aB}$ & $72,4 \mathrm{aA}$ \\
\hline & \multicolumn{4}{|c|}{$1999 / 2000$} \\
\hline $21 \mathrm{DAS}$ & $0,0 \mathrm{aA}$ & $1,9 \mathrm{aA}$ & $0,0 \mathrm{aB}$ & $9,3 \mathrm{aA}$ \\
\hline 5 DAS & $0,2 \mathrm{aA}$ & $0,0 \mathrm{aA}$ & $1,2 \mathrm{aA}$ & $0,0 \mathrm{bA}$ \\
\hline $34 \mathrm{DDS}$ & $0,5 \mathrm{aA}$ & $3,1 \mathrm{aA}$ & $4,0 \mathrm{aB}$ & $14,8 \mathrm{aA}$ \\
\hline Subtotal & $0,7 \mathrm{cA}$ & $5,0 \mathrm{cA}$ & $5,2 \mathrm{bB}$ & $24,0 \mathrm{cA}$ \\
\hline Total & $41,5 \mathrm{~B}$ & $79,6 \mathrm{~A}$ & $71,4 \mathrm{~B}$ & $135,4 \mathrm{~A}$ \\
\hline
\end{tabular}

(1)Datas de semeadura: 30/10/1997, 29/10/1998 e 26/10/1999; médias seguidas pelas mesmas letras, minúsculas nas colunas e maiúsculas nas linhas, não diferem entre si pelo teste de Tukey a $5 \%$ de probabilidade. ${ }^{(2)}$ DAS: dias antes da semeadura; DDS: dias depois da semeadura. 
As densidades de plantas de balãozinho decresceram de ano para ano, em razão do ataque de míldio, tendendo a uma maior infestação na SD, que foi significativa só no último ano (Tabela 3). As alturas médias de plantas de soja foram menores nos manejos do primeiro ano, em relação aos anos seguintes, provavelmente pela ocorrência de menores quantidades de chuvas no período reprodutivo (Tabela 4). As produtividades médias de soja foram menores no primeiro ano em relação aos dois anos seguintes, não ocorrendo diferenças entre os manejos (Tabela 3).

A perda de produtividade de soja em decorrência das densidades de plantas de balãozinho, foi maior, em termos absolutos, na SD, no primeiro ano (33\%) (Tabela 5). No segundo ano, as perdas foram maiores na SC e no terceiro ano, as perdas foram inexistentes na SC, com a inexpressiva presença de 1,5 plantas $/ \mathrm{m}^{2}$, sendo elevada na SD, com 6,6 plantas $/ \mathrm{m}^{2}$. As relações de perdas por unidade de balãozinho foram muito variáveis.

Cálculos de perdas de soja, baseando-se nas médias dos manejos do primeiro ano, foram de $28,8 \mathrm{~kg} / \mathrm{ha} /$ planta de balãozinho e, admitindo-se que a presença de 10 plantas $/ \mathrm{m}^{2}$ provoque uma perda de $288 \mathrm{~kg} / \mathrm{ha}$, obterse-ia uma estimativa de $8,1 \%$ de perda sobre a produtividade média de soja, de $3.549 \mathrm{~kg} / \mathrm{ha}$ (Tabela 5). Souza (1995) relatou uma perda de $26 \%$ pela convivência com 10 plantas de balãozinho/ $/ \mathrm{m}^{2}$, para produtividade semelhante. As perdas do segundo ano, na SC e, do terceiro ano, na SD, revelam que as perdas por unidade de balãozinho podem aumentar, aproximando-se mais da

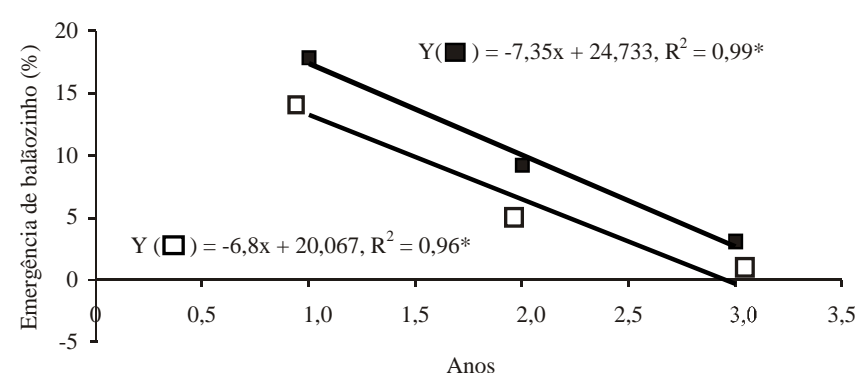

Figura 2. Níveis de emergência anual de balãozinho, numa seqüência de três anos, a partir de um banco de sementes inicial de 480 sementes $/ \mathrm{m}^{2}$, nos manejos de semeadura convencional $(\square)$ e direta competição atingida por Souza (1995). Pode-se ainda inferir que as condições de competição verificadas neste trabalho foram menos favoráveis ao crescimento do balãozinho do que as observadas por Souza (1995) no Rio Grande do Sul, acrescentando-se a ocorrência do ataque da doença de míldio.

Tabela 3. Densidades de plantas de balãozinho competindo nos manejos de semeadura convencional (SC) e direta (SD) da soja cultivar Embrapa 62, nos anos de 1997/1998, 1998/ 1999 e 1999/2000 e efeito dessas densidades na altura de plantas e produtividade de soja ${ }^{(1)}$.

\begin{tabular}{|c|c|c|c|}
\hline \multirow{2}{*}{$\begin{array}{c}\text { Sistema } \\
\text { de manejo }\end{array}$} & \multicolumn{3}{|c|}{ Ano } \\
\hline & 1997/1998 & 1998/1999 & $1999 / 2000$ \\
\hline & \multicolumn{3}{|c|}{ Densidade de balãozinho (plantas $\left./ \mathrm{m}^{2}\right)$} \\
\hline $\mathrm{SC}$ & $34,0 \mathrm{a}$ & $15,8 \mathrm{a}$ & $1,8 \mathrm{~b}$ \\
\hline SD & $40,7 \mathrm{a}$ & $23,6 \mathrm{a}$ & $8,9 \mathrm{a}$ \\
\hline \multirow[t]{2}{*}{ Média } & $37,4 \mathrm{~A}$ & $19,7 \mathrm{~B}$ & $5,4 \mathrm{C}$ \\
\hline & \multicolumn{3}{|c|}{ Altura de plantas de soja $(\mathrm{cm})$} \\
\hline SC & $64,9 \mathrm{a}$ & $88,0 \mathrm{~b}$ & $78,5 b$ \\
\hline SD & $64,7 \mathrm{a}$ & $94,5 \mathrm{a}$ & $91,8 \mathrm{a}$ \\
\hline Média & $64,8 \mathrm{~B}$ & $91,2 \mathrm{~A}$ & $85,2 \mathrm{~A}$ \\
\hline & \multicolumn{3}{|c|}{ Grãos (kg/ha) } \\
\hline $\mathrm{SC}$ & $3.041 \mathrm{a}$ & $3.385 \mathrm{a}$ & $3.770 \mathrm{a}$ \\
\hline SD & $3.030 \mathrm{a}$ & $3.432 \mathrm{a}$ & $3.179 \mathrm{a}$ \\
\hline Média & $3.036 \mathrm{~B}$ & $3.408 \mathrm{~A}$ & $3.474 \mathrm{~A}$ \\
\hline
\end{tabular}

Tabela 4. Dados médios de precipitação pluvial (mm) e temperatura média nos anos de 1997/1998, 1998/1999 e 1999/2000, em Londrina, PR.

\begin{tabular}{llcc}
\hline Ano & Mês & $\begin{array}{c}\text { Precipitação } \\
(\mathrm{mm})\end{array}$ & $\begin{array}{c}\text { Temperatura } \\
\text { média }\left({ }^{\circ} \mathrm{C}\right)\end{array}$ \\
\hline 1997 & Out. & 135 & 21,6 \\
& Nov. & 279 & 22,7 \\
& Dez. & 128 & 24,5 \\
1998 & Jan. & 115 & 24,5 \\
& Fev. & 270 & 24,0 \\
& Mar. & 229 & 23,5 \\
& Out. & 151 & 20,9 \\
& Nov. & 49 & 23,1 \\
& Dez. & 266 & 23,6 \\
& Jan. & 205 & 23,4 \\
& Fev. & 133 & 23,9 \\
& Mar. & 77 & 23,8 \\
& Out. & 93 & 20,9 \\
& Nov. & 39 & 21,9 \\
& Dez. & 103 & 24,3 \\
& Jan. & 120 & 24,0 \\
& Fev. & 168 & 23,3 \\
& Mar. & 75 & 22,5 \\
\hline
\end{tabular}


As equações hiperbólicas foram as que proporcionaram melhor ajuste aos dados observados, dentro de cada sistema de manejo e ano de condução do experimento

Tabela 5. Perdas de produtividade de grãos de soja cultivar Embrapa 62, em razão de densidades de plantas de balãozinho (perda 1 = redução porcentual; perda $2=$ redução em $\mathrm{kg} / \mathrm{ha}$ de grão de soja por planta de balãozinho) nos manejos de semeadura convencional e direta de soja.

\begin{tabular}{lccrr}
\hline Ano & $\begin{array}{c}\text { Balãozinho } \\
\left(\text { plantas } / \mathrm{m}^{2}\right)\end{array}$ & $\begin{array}{c}\text { Soja }(\mathrm{kg} / \mathrm{ha}) \\
\text { (testemunha) }\end{array}$ & Perda 1 & Perda 2 \\
\hline \multicolumn{5}{c}{ Semeadura convencional } \\
$1997 / 1998$ & 26,5 & 3.486 & 19,5 & 25,6 \\
$1998 / 1999$ & 13,3 & 3.992 & 18,0 & 54,0 \\
$1999 / 2000$ & 1,5 & 3.796 & 0,0 & 0,0 \\
\hline \multicolumn{5}{c}{ Semeadura direta } \\
$1997 / 1998$ & 25,7 & 3.613 & 33,0 & 32,0 \\
$1998 / 1999$ & 14,3 & 3.732 & 11,2 & 29,2 \\
$1999 / 2000$ & 6,6 & 3.464 & 8,0 & 42,0 \\
\hline
\end{tabular}
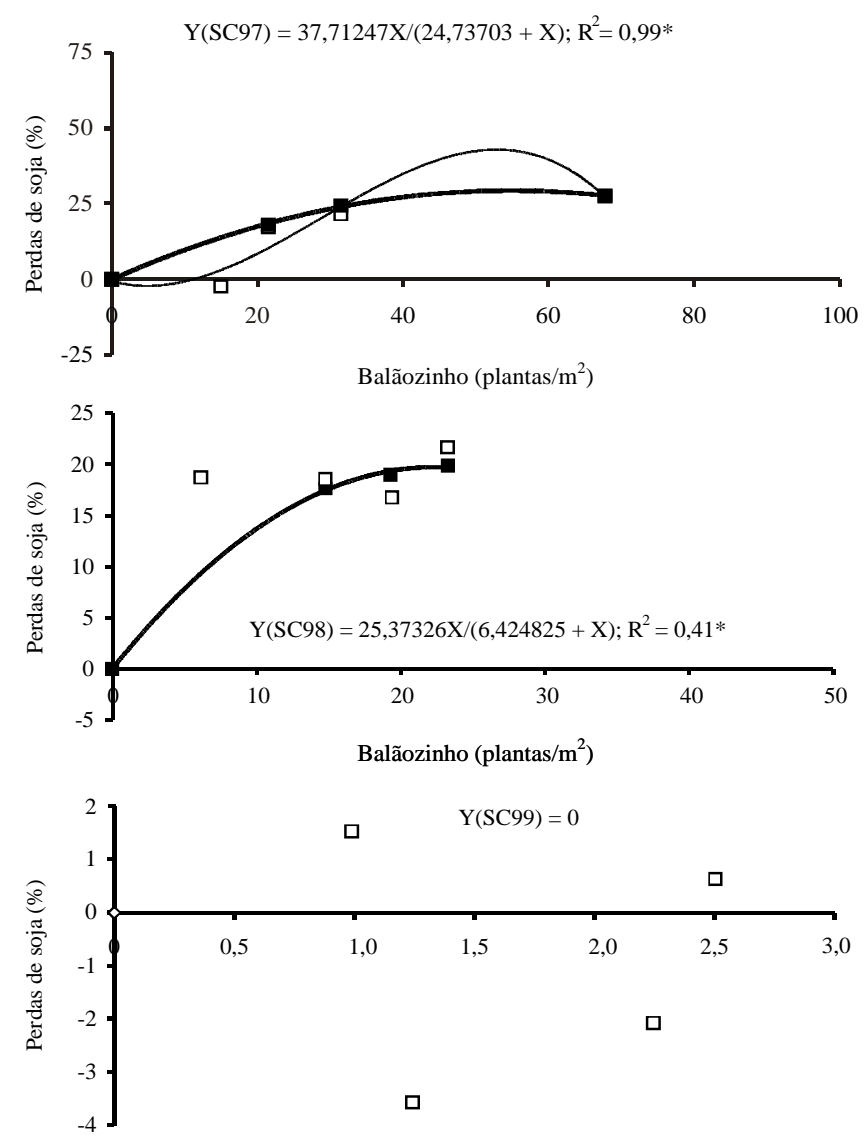

Balãozinho (plantas $/ \mathrm{m}^{2}$ )
(Figura 3). Reduções na produtividade de soja foram verificadas com o aumento das densidades de plantas de balãozinho. Produtividades de soja obtidas na densidade de 10 plantas de balãozinho/ $\mathrm{m}^{2}$ não foram diferentes da testemunha, sem competição, em ambos os manejos, em 1997/1998. Observou-se um ganho de produtividade com a densidade mais baixa de balãozinho, projetando perdas maiores entre as duas últimas densidades, com posterior declínio, e possível competição intraespecífica. No ano de 1997/1998, constatou-se um ataque intenso de Peronospora farinosa (míldio), que destruiu a parte aérea das plantas de balãozinho, antes do período de maturação da soja, sem prejudicar a colheita. O ajuste hiperbólico em 1998/1999, para a SC, foi baixo $\left(\mathrm{R}^{2}=0,41\right)$. As perdas de produtividade de soja, de cerca de $20 \%$, não diferiram entre si nas densidades
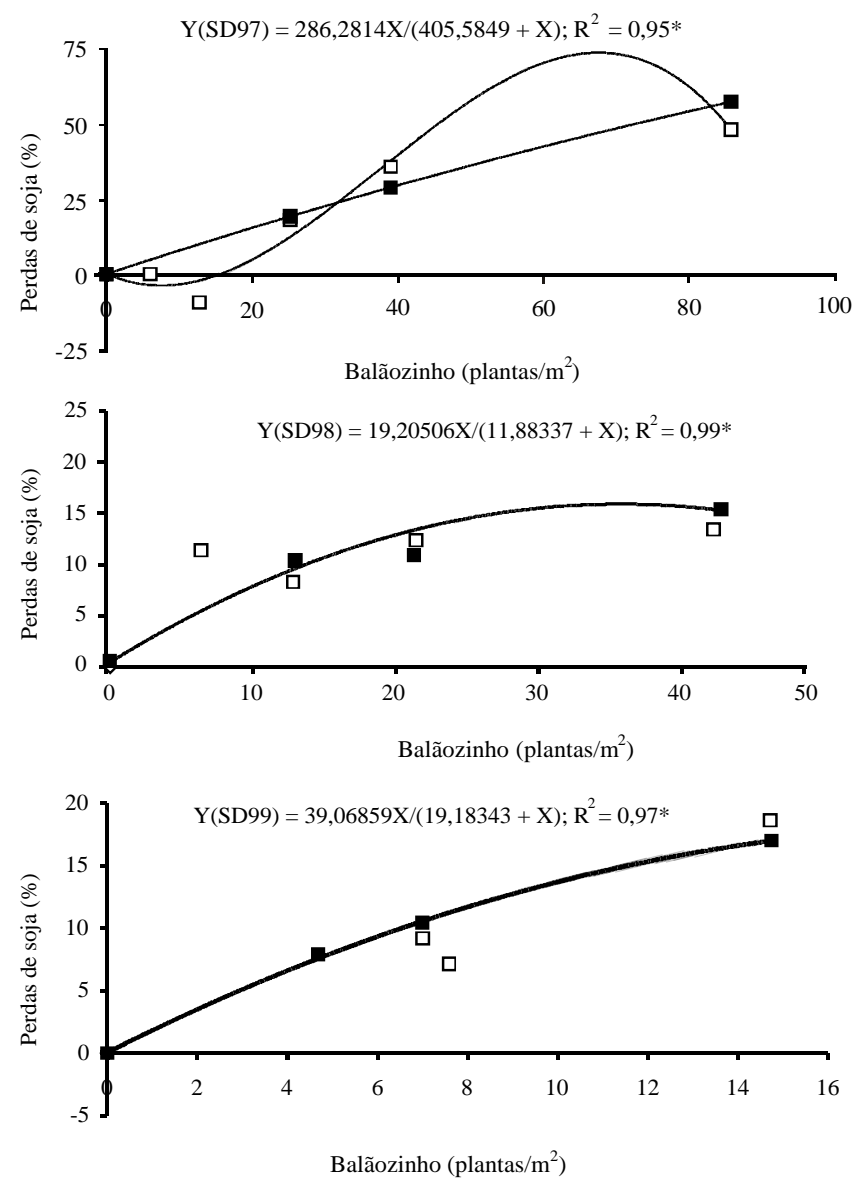

Figura 3. Ajuste de equações parabólica (—) e projeção polinomial (—), obtidas para estimativas de perdas de produtividade de soja em função da intensidade de competição de plantas de balãozinho, nos períodos de 1997/1998, 1998/1999 e 1999/ 2000, nos manejos de semeadura convencional (SC, $\square$ ) e direta (SD, $\square$ ) da cultura. 
entre 5 e 25 plantas $/ \mathrm{m}^{2}$. Na SD com cerca de 45 plantas $/ \mathrm{m}^{2}$, ocorreu um alto ajuste dos dados $\left(\mathrm{R}^{2}=0,99\right)$, com perda máxima de soja de cerca de $15 \%$. O ajuste hiperbólico de 1999/2000, na SC, não ocorreu com a infestação máxima de balãozinho, de 2,5 plantas $/ \mathrm{m}^{2}$; na $\mathrm{SD}$, ocorreu alto ajuste $\left(\mathrm{R}^{2}=0,97\right)$, com cerca de 15 plan$\mathrm{tas} / \mathrm{m}^{2}$ e perda máxima de soja de cerca de $17 \%$.

\section{Conclusões}

1. O balãozinho apresenta capacidade de infestação e competição com a cultura da soja.

2. As plantas de balãozinho apresentam suscetibilidade ao ataque de míldio (Peronospora farinosa), que reduz a produção de sementes.

3. A emergência de plantas em pré- e pós-semeadura da soja é maior no sistema de semeadura direta do que no convencional.

4. Na ausência de reinfestações anuais, os propágulos no solo e as respectivas taxas de emergência tendem a diminuir.

\section{Agradecimentos}

Ao Conselho Nacional de Desenvolvimento Científico e Tecnológico (CNPq), pelo apoio financeiro.

\section{Referências}

CABRERA, E.R.; DIAZ, J. Removal of balloonvine (Cardiospermum halicacabum L.) seed from soybeans using an electronic colour sorting machine. Seed Science and Technology, v.19, p.203-206, 1991.

COUSENS, R. A simple model relating yield loss to weed density. Annals of Applied Biology, v.107, p.239-252, 1985.

FUNDAÇÃO INSTITUTO AGRONÔMICO DO PARANÁ (Londrina, PR). Cartas climáticas básicas do Estado do Paraná, 1978. Londrina, 1978. 41p.

JOHNSTON, T.J.; MURRAY, D.S.; WILLIAMS, J.C. Germination and emergence of balloonvine (Cardiospermum halicacabum) compared with soybean seeds. Weed Science, v.27, p.73-76, 1979.

LORENZI, H. Plantas daninhas do Brasil: terrestres, aquáticas, parasitas e tóxicas. 3.ed. Nova Odessa: Instituto Plantarum, 2000. $608 \mathrm{p}$.

RAO, A.P.; RAO, A.S. New fungal diseases of some weeds. Indian Botanical Reporter, v.6, p.38, 1987.

SOUZA, R.O. de. Balãozinho (Cardiospermum halicacabum L.) na cultura da soja (Glycine max (L.) Merril): aspectos biológicos e controle químico. 1995. 82p. Dissertação (Mestrado) - Universidade Federal de Santa Maria, Santa Maria.

SOUZA, R.O.; RUEDELL, J. Levantamento populacional das principais plantas daninhas nos cultivos de verão: relatório técnico - safra 1993. Cruz Alta: Fundacep/ Fecotrigo, 1993. 5p.

Recebido em 27 de maio de 2003 e aprovado em 6 de novembro de 2003 